\title{
Progress and Cumulation in the Human Sciences After the Fall
}

\author{
Mayer N. Zald ${ }^{1}$
}

What do we mean by progress and cumulation in the social and human sciences? Recent thinking in the philosophy and history of science has led to an abandonment of some versions of logical positivism and of verificationism that had a strong deductive and theory testing orientation. What is to replace them is less clear. This paper argues that progress and cumulation can be seen as a process of evaluation and retention within an epistemic community. Scholarly disciplines differ in their social structure and in their epistemic and normative commitments. Since sociology is a fragmented discipline, progress and cumulation differ within its multiple subdisciplines, which to varying extents represent epistemic communities. Brief sketches of progress (advance) and cumulation in several subdisciplines are offered.

KEY WORDS: progress and cumulation in social and human sciences; philosophy of science; history of science; logical positivism; deduction; theory testing.

\section{INTRODUCTION}

The sciences rest their claims to superiority over other methods of revealing truth (e.g., philosophy, theology, literature,) on two related bases-superior methods for accepting or rejecting truth claims (e.g., controlled observation, experimentation) and methods for cumulating and organizing truth claims (e.g., classification systems, theories, propositional inventories). The sciences are (were) thought to be progressive, systematically eliminating error or falsehood and cumulating knowledge. For much of this century, the social sciences, especially in the United States, attempted to emulate the physical and natural sciences. Positivistic methods in the social sciences were thought to be superior to interpretivistic, phe-

'Department of Sociology, University of Michigan, Ann Arbor, Michigan 48109. 
nomenological, and text analytic approaches to arriving at the truth. ${ }^{2}$ Even when a discipline eschewed the generalizing (nomothetic) aims of theoretically driven science, practitioners thought they could progress by adhering to rigorous modes of data collection and data analysis.

While many physical scientists continue to believe in the positivistic view of progress and cumulation, with its attendant materialist and mechanistic ontologies and its epistemic coordination of theories, measurement, and observation, historians and philosophers of science have increasingly challenged that vision. The fall from foundationalism not only challenges the epistemological grounds of science, it also has implications for conceptions of progress and cumulation. On the one hand, post-Kuhn, few believe that theories are largely supplanted through critical tests, or through the formulation of more general encompassing frameworks. The language of paradigm succession or shift seemed much more ambiguous and open to social and cultural processes than the language of positivism and verificationism suggested. Although Kuhn (1977) has continued to believe in the progressive character of science, what progress means has become ambiguous. Science is a more disorderly and disunified enterprise than some philosophies of science had suggested.

Post Rorty, philosophers and historians of science tend to believe that the act of observing the world is deeply influenced by the language system - the linguistic categories, embedded metaphors, and rules for using language. There is a world out there, but we only know it through a socially constructed language system. An epistemology that assumes a mapping is in some sense a logical impossibility, because as we speak about it, the world as we know it is already language and theory prefigured. Indeed, even this phrasing artificially separates language/practice from its constitutive role in human-world embeddedness (Rouse, 1987).

Not only is positivism a misleading doctrine for the natural sciences, but, say interpretivists, for the social and human sciences it is doubly misleading. What is to be observed and understood is a meaning system and its implications. Most of the "brute facts" that are subject to enumeration in positivistic social science gain their force because of the cultural/social meanings in which the subjects of social science participate (Taylor, 1971). Explanation in the causal sense must give way to, or be embedded in, hermeneutic unveiling and interpretation.

${ }^{2}$ Positivism has come in many guises. Anthony Giddens (1978) traces its connections to sociology and its vicissitudes. Here I use the term to characterize an epistemological position that aims for universal abstracted generalizations, or laws, connected to objective observation. 
Now, how might we think of progress and cumulation after the fall? ${ }^{3}$ If older verificationist and/or logical positivist models seem less useful, what can we substitute for them? Specifically, how might we think of progress and cumulation in the human and social sciences? Beginning from an antifoundationalist and antiunificationist set of assumptions (Dupre, 1993), I want to argue, first, that some notion of progress (advance) is a central ordering or control device in the community of scholars. It is a criterion we use in evaluating scholarly products, in judging dissertation proposals, in evaluating journal articles, in praising or condemning studies. It is part of local practice. Second, the notions of progress and cumulation are themselves social and rhetorical constructs that vary among disciplines and subdisciplines. Moreover, there may well be a difference between the evaluation and conception of progress within a discipline or subdiscipline and relevant external audiences-which may include other communities of scholars. This disjunction may have grave implications for the reputation and economic status of the subdiscipline. Third, the conception of progress and cumulation is tied to the structure and epistemic assumptions of scholarly communities; thus we must ask what are these communities' relevant dimensions for understanding conceptions of progress? Fourth, what are the implications of this discussion for progress and cumulation in sociology and for the human sciences as a whole?

To foreshadow the argument, I will argue the following: (a) Progress and cumulation are separate or separable issues. Moreover, progress and cumulation are subject to rhetorics of stylization or modelling and rhetorics of use or practice. (b) The operative epistemic and methodological assumptions or commitments of sociological subdisciplines vary enormously; these epistemic/methodological assumptions structure the criteria for progress in subdisciplines and shape the linguistic form of truth claims and the "architectonics" of the system of truth claims. (c) In many subdisciplines in sociology there has been great progress, but, paradoxically, in some of the same areas where there has been great progress, there has been little cumulation. (d) Finally, because some of the human sciences are deeply connected to the political and social concerns of the day, the changing agenda of society reshapes the animating concerns of scholarly disciplines. Again paradoxically, cumulation may occur most in subdisciplines least tied to the intellectual currents of the day, as scholars are tied to a more limited range of concerns; however, great leaps of progress, in the sense of innovative

\footnotetext{
${ }^{3}$ Obviously, Kuhn and Rorty were not alone in creating the fall from foundationalism, especially the stylized received version of logical positivism. Moreover, as Lowell Hargens has noted in a personal communication, many philosophers and historians of science never bought into all of the strict strictures ascribed to logical positivism. Indeed, Hempel, usually seen as the opposite of Kuhn, influenced him and was not hostile to his efforts (see Horwich, 1993).
} 
ways of looking at issues, may occur in those subdisciplines most attuned to the larger currents of society.

\section{REFLECTIONS ON PROGRESS AND CUMULATION: RHETORICS AND USAGES}

Reflect on everyday usage. To make progress is to advance, to move forward. To progress is not just movement, but forward movement. Movement backward, or energy expended to stay in place, is less often considered progress; it has to be argued for, justified. Progress has a temporal and/or spatial component. It implies some comparison with a previous state or a potential future state. Progress usually implies a goal, either an objective, however loosely defined, or a comparison of states of knowledge on some implicit or explicit criterion; it is measured against a stylized or idealized state of being, or is a comparison of two or more alternatives, including the current state of knowledge.

Although it is common to think of progress, especially in science, as a good, progress can be tied to dark ends, witness Hogarth's The Rake's Progress. In scholarship a dark sense of progress, a path toward the abyss, is sometimes attributed to work that appears to be nihilistic and to have a destructive edge without promoting alternatives. Ethically, a dark side of progress is found in the release of destructive and uncontrollable consequences of scientific advance.

The word "progress" can be associated with modernity and the enlightenment program linking rationality and improvement. A lively debate in contemporary philosophy of science revolves around exactly how much scholars such as Kuhn actually depart from a modernist, progressive view of scientific achievement (Rouse, 1991). For our purposes, without privileging science over everyday and practical knowledge, and without making claims for science in its overall contribution to human welfare, we will start from an assumption that the human sciences and its practitioners are organized around, are oriented toward, some notion of advance, better understanding or superior truth claims.

Progress or advance in intellectual matters implies doing things better along some dimension relevant to the task. Better methods, new observations or observation methods, greater certainty, more aesthetically pleasing ways of representing, more satisfying interpretations of events, all qualify as making progress. So too does discarding falsehoods and rejecting theories. Notions of creative destruction suggest progress by elimination, or by eliminating residuals, to make way for new advances in knowledge or competencies. 
Pre Kuhn, cumulation and progress were seen as in some sense linear. There was little room for backsliding, for losing knowledge. Facts cumulated as more studies were done; theories cumulated as successive formulations became more general and encompassing. The truths of an early theory were contained within the new formulation. Post Kuhn and post Rorty matters are more complicated, since facts are not independent of theory laden language and since both depend upon often unexplicated assumptions and frames. When paradigms shift there may be losses of knowledge and knowledge creating potential since the older paradigms may be better for pursuing certain kinds of questions than the newer paradigms, even though the newer paradigms are better for the problems at hand.

Philosopher Larry Laudan (1977) avoids some of these issues by focusing on progress as problem solution. Admitting that there may be losses as well, he takes progress to be the resolution of problems-in the formation of concepts and in their linkage in explanatory and mathematical systems, in measurement, in data collection and data analysis, as perceived by the working community of scholars.

Increasingly scholars have seen progress as a process in which a community of scholars working with a set of (often implicit) consensus practices comes to accept new practices and ideas. Both the history of those practices and ideas, and the organization of the community, play a large role in what is on the table at any point in time and how new ideas and solutions will be evaluated (Kitcher, 1993; Rouse, 1990). The state of a field is socially and historically constructed; what is on the table is to some large extent the residue or result of prior siftings, debates, and discourse. Consensus is not easily won. Indeed, as Gilbert and Mulkay (1984) demonstrate for the case of the chemiosmotic rationale in the field of photosynthetic phosphorylation, even when a consensus emerges that a once renegade theory is in fact important and valuable, the meaning of the theory and its fit in the field of knowledge may still be open to debate.

Modernist philosophies of science argued not only that science advances, but that it leads to more encompassing and unified systems of explanation. In this way of thinking, advance leads to cumulation through the successive retention of superior theories and the assimilation of facts to those theories. Yet advance and cumulation are separable processes. Possibly because philosophy of science had on its agenda issues of epistemology and the establishment of truth, it had less to say about the retention or $\mathrm{cu}$ mulation of "truths" once they were established. Even today, discussions of scientific advance tend to say less about the problem of cumulation than about the problem of progress. Cumulation is somehow seen as automatic. Yet Stephen Cole $(1992,1994)$, a leading sociologist of science out of the Mertonian framework, argues that it is precisely the difference in commu- 
nities' abilities to agree on what is the core (the retained knowledge handed on to the next generation as accepted practices and ideas) and to assimilate knowledge to the core that distinguishes "real sciences" from the protosciences. For Cole, all scientific fields have dissension at the "frontier," but some do not appear to be organized to adjudicate, decide, and retain important findings, theories, and concepts.

Just as progress might come in several guises, so too may cumulation occur in several forms. One form of cumulation, accumulation, registers observations, preferably replicable observations. In its most empiricistic form, cumulation is the systematic registering of facts. But, say the more theoretically inclined, empiricistic cumulation is a kind of random cumulation - a growing mountain of assorted tidbits organized only around agreed upon categories of observation; what is needed is a mechanism for selecting important observations, or selecting important and precisely explained or predicted observations. Classification systems, theories, and related mathematical formulations become more explicit guides for organizing the retention of knowledge and guiding future research.

Cole (1994) argues that agreeing on the core depends upon having stable objects to explain; general theory and their elementary components in sociology are vacuous and nongeneral phenomena are too subject to changes (e.g., gender relations). One might also argue that the agenda of some parts of sociology is tied to recent political and morally charged events and trends in society; thus, it is not just change within the objects of concern that creates instability for social scientists, but changes in the focal problems of concern. Here the lack of cumulation is caused not by changes within the object of analysis, but by which objects come, and stay, on the table (Zald, 1991). In the natural and physical sciences, findings, facts, and generalizations become assimilated to the background assumptions of the problems that are on the table. However, in some parts of the social sciences, shifts within objects or in the topics of concern, make irrelevant those findings or generalizations from what was once the frontier.

The distinction between core and frontier hides the possibility that even among disciplines that have relatively stable objects, the architectonics of cumulation may differ. Ernst Mayr (1982) argues that the growth of biological thought has occurred not through the development of universal laws, but through the articulation of major concepts. The scaffolding of cumulation is created by the addition of new concepts that bracket fields of investigation and explanations. While it is possible to attempt to formulate laws, that is not how biologists have actually proceeded. Extending Mayr's argument, and without prejudging whether succeeding theories, systems or facts are in an absolute sense truer than earlier ones, different fields organize their truth claims about, and their representations of, their objects 
of analysis by different modes. Musicologists, literary theorists, anthropologists, physicists, and sociologists differently privilege classification systems, theories, concepts, notation systems, and so on. In some sense, all use texts to communicate and cumulate, but the organization of textual representation and the link of the texts to communities of practice will vary.

\section{RHETORICS OF PROGRESS AND CUMULATION}

So far I have treated the issue of progress and cumulation as a kind of natural category or language used by a community of scholars to guide research decisions and to present and organize discourse. But progress and cumulation are also subject to abstract discussion, emulation, and stylization, as scholars within a community reflect on and discuss their own practices and interact with scholars from other disciplines, as well as the interpreters and translators of those disciplines-philosophers, historians, sociologists, who render the logics and practices of disciplines. Stylized rhetorics develop such that practitioners who do not use them are treated as less advanced than those who do. At an earlier time, physicists who did not use mathematics were seen as less competent than those who did. Today, all do. Over the last century, the mathematicization of economics, called "physics envy" by some, has proceeded whether or not it was appropriate to the more important problems in the field (McCloskey, 1985). In sociology, the belief in formal deductive theorization led to a style of presentation that required the formal statement of axioms and hypotheses, even if the logic of the argument was really contained in the explanatory paragraphs accompanying the propositions and derived hypotheses (cf. Zetterberg, 1963). The rhetorics of cumulation sometimes showed in the publication of propositional inventories (Berelson and Steiner, 1964).

It is probably inherent in the human condition for people who happen to be scholars to reflect on their own practices and to compare them with past practices, with the practices of others, and with abstracted models of practice. Yet, more self-confident and autonomous groups of scholars are less likely to take seriously what others are doing or saying about what disciplinary practice should be. They may have an internal debate about what progress is, but the debate will be drawn largely from an internal logic of practice and aspirations within a discipline or community, rather than organized by and contrasted with abstracted views of science and scholarship or other disciplines practices. This is an aspect of the internalization of disciplines (Shapere, 1984).

Moreover, explicit concern with progress and cumulation may vary by disciplines and context. The collective project of legitimizing the natural 
and physical sciences, especially in England and the United States, led them to contrast themselves with the humanistic disciplines on the criteria of progress and cumulation. In turn, the social sciences, once called moral sciences, attempted to nestle close to the physical and natural sciences. Scholars in the humanistic disciplines surely make judgments about advances in their disciplines. New modes of annotation, classification, and interpretation are judged superior in explaining, illuminating, and gathering together observations about the objects of humanistic understanding. They may be less likely to articulate a research or theoretical frontier, because some are organized around interpretative topics, not "problems." That does not mean, however, that better interpretations-interpretations that are more coherent, more illuminating, more closely tied to evidence-cannot be judged and handed down to successive generations.

To summarize the thrust of the argument so far, progress and cumulation are interconnected but separable concepts; progress has more to do with advance, and cumulation has to do with the storage, transmission, and recycling of advances for further research and knowledge building. Both concepts are "fuzzy," and forms of advance and cumulation may be multiple. Stylized rhetorics about progress and cumulation may be borrowed from other disciplines and imposed on subject matters, just as techniques of investigation or concepts may be borrowed. Finally, since disciplines vary in how they organize knowledge and make advances, progress and cumulation must be understood in the context of disciplinary practices and commitments, and in the context of the texture of scholarship.

\section{The Texture of Scholarship and Epistemic Communities}

Anthropologist Roy D'Andrade (1985) argues that it is useful to think about three models of scientific disciplines-physical science, natural science, and semiotic science. He argues that the physical sciences-physics, astronomy, and chemistry - can be well described by the covering law model and are most appropriately mathematicized. The natural sciences, which include the biological sciences and some of the social and earth sciences, have a different texture. They describe adaptive systems, typically components of systems and their interaction with other components. Functioning systems' mechanisms of adaptation are important elements. Semiotic sciences-cultural anthropology, much of social psychology, and components of linguistics-deal with systems of meaning. Following the psychologist Thomas Lauduaer, d'Andrade argues that experimental social psychology is often a special way of doing American ethnography. The social sciences, he says, often require both natural system and semiotic approaches. It is, 
for instance, possible to describe capitalist societies as systems of interconnecting parts. However, for many purposes semiotic analysis of the (changing) meaning of the system and its components will be required.

He does not argue that mathematicization is restricted to the physical sciences, only that it is less prominently featured in the others and will often be subsidiary to the description of components. D'Andrade uses his threefold categorization to argue that form of argument, the nature of generalization and, by implication, the logic of progress and cumulation, will look very different from discipline to discipline. However, aside from arguing against the usefulness of a covering law formula, and distinguishing system like disciplines from semiotic ones, he does not spend much time discussing how texture of scholarship might vary by disciplines and subdisciplines. Moreover, the broad sweep of his categorization conceals large differences within scientific/scholarly fields. It also fails to explore the complex linkages between parts of fields (subdisciplines, or invisible colleges) and to subdisciplines nominally located in other disciplines.

Texture is a global term for the ways in which discourse in a community is conducted. It is rhetorics in its most inclusive and nonpejorative sense. It refers to the mix of linguistic/symbolic representations and the conventions governing their use in a community. Everything from mathematical formulae, to the presentation of graphics, to footnote conventions are part of the texture of a community's discourse. Different textures lead to different modes of reporting advances and summarizing whole fields. A review article in history will look very different from a review article in physics. Textures or rhetorics are both products and creators of epistemic communities.

Scholarly communities are epistemic communities. They have what Margaret Somers (forthcoming) calls "knowledge cultures" or what Ian Hacking (1984) calls "styles of reasoning." Earlier, Fleck (1935/1979) even used the term "thought collective" to refer to the shared communal understandings.

How might we describe epistemic communities? First, they are organized around topics. Second, the scholarly community has a repository of more or less organized findings, and claims about findings, in its accumulated and retrievable stock of writings and oral claims about the topic. Third, the community has a set of methodological commitments and claims about how findings are to be obtained. Fourth, the community has a set of implicit and explicit assumptions about what the repertoire of constituting ideas, interpretations, and explanations that can be entertained to order research, to choose among renderings and readings, and to focus activity.

To talk about progress and cumulation, then, is to talk about change in the stock of knowledge, methods, and assumptions in particular commu- 
nities of scholars. Since these communities may have different and deep methodological commitments, orientations toward data collection and analysis, etc., it might be possible, though beyond my scope here, to develop a comparative analysis of epistemic commitments. Central are a description of the kinds of observations and readings made on objects (natural or human made), the forms of summarization (quantitative, graphic, visual), and the language structure (mathematical, statistical, propositional, universal extension, etc.), used to interpret and order the observations.

Any particular scholar may be part of several communities. For instance, a scholar may be a student of Marxism in American social history studying mining towns and working with quantitative indicators of collective action. Or, a rational choice Marxist working on collective action in mining communities. Depending on the scholar's own capacities and predilections, she might be more or less attuned to debates and issues in adjoining or overlapping fields of study (e.g., psychoanalytic studies of 19th-century child-rearing practices in the working classes). Donald T. Campbell (1969) describes this overlap, or interlink, of communities of scholars as the "fish scale model" of interdisciplinary overlap. One form of progress is constituted by forming new communities. Over time, scholars may discover topics untreated by, and disjunctive with, the stock of problems within a community. The very recognition of the separateness of the problem set is a form of progress.

Over time the epistemic community produces a set of problems to be solved. One of the differences among communities is, of course, the amount of agreement about when a problem is solved or what constitutes a solution. The problem set may be relatively stable, and indeed so called solutions may represent interpretations that only crowd in on earlier interpretations, forcing them to the background without in any sense vanquishing them. However, the problem set may be changing rapidly, with or without consensus on solution. This juxtaposition of problem stability and change and consensus on the meaning of change is especially important for thinking about cumulation and progress. Where there is rapid change in problems studied or solutions suggested for those problems, and little consensus about either the importance of the problems or the solutions being offered, charges of faddism, as opposed to advance, are likely to be made.

Communities of scholars are not only epistemic communities. They participate in a social organization that rewards and punishes behavior. Communities of scholars are organized around communications about the central topic(s) - through journals, books, conferences, and scholarly societies. They are not the same as, though they overlap with, disciplines. They are made up of members - those people who are "credentialled" to speak 
on the topic. Credentialing can be formal or informal, but the uncredentialed have a tough time getting a hearing in the community. Credentialing occurs through complex processes. It is especially important for the warranting of findings and perspectives that break from the established repertoire. It may be that membership within the community is heavily dependent upon certification of methodological competence, e.g., the ability to do fieldwork, to use archives, to use mathematics, to do laboratory work, and to have command of relevant rhetorical forms (e.g., footnotes and footnote practice, modes of argumentation, and presentation of data forms). Many disciplines may have multiple certification routes. Moreover, in an era of blurred disciplinary/community boundaries, scholars may be at home in and received by multiple communities.

Communities of scholars allocate prestige and have an internal stratification system that links contributions to the community to material and symbolic rewards, including jobs. Communities may vary in the uniformity and coherence of their stratificational/allocational systems. Those high in the system act as gatekeepers by evaluating contributions to the community. They may not be the first to recognize the contribution to progress in the community, and over time they may be replaced, but because the gatekeepers control access to journals, jobs, awards, career movement, and acceptance of dissertations, at some point progress is validated within the prestige system of the community. Stinchcombe (1994) argues that the fragmented nature of sociology leads to many errors in the evaluation of work and the placement of sociologists in the academy, presumably in contrast to more unified, coherent disciplines.

Communities of scholars vary enormously in their density and size, the number of scholars at any one time working on a set of related topics, or indeed, on the same problem within a topic field. The number of scholars working on the same problem and related topics creates both a validation and replication ground for the "truth" or "interpretative truth" claim, and a user field for demonstrating the value of the claim over time. The distinction is not sharp, of course. Nevertheless, in many fields there may be a debate in which scholars address their work largely to peers thinking at the same level of abstraction and discourse (the validation and replication ground) and a group who use the arguments, concepts, and findings to illuminate their own extensions and applications of the argument. In other fields, few scholars may actually work on the same problem, but may share a discursive field and orientation.

In many parts of the social and human sciences, exact replication and similar problem focus may be rare, though a sense of participating in a larger common topical area or orientation may be common. For instance, many scholars are now concerned with the emergence, maintenance, and 
force of nationalism in social structure and ideology, though few with nationalism in 18th-century Bosnia, or some other specific locale. They share a general discursive field and may rely on classic and contemporary texts that compare nationalist movements or discuss nationalism more generally.

Finally, communities of scholars differ substantially in their "nodality," the extent to which scholars are clustered around organizational settings, such as research institutions - astronomy labs, survey research centers, or schools and publication outlets of like-minded scholars. As Whitley (1984) shows, the institutional/organizational nodality of a community affects the acceptance of truth claims and the orientation of research, at least in the short run.

This discussion of the epistemic texture and social organization of communities has been developed in order to get purchase on the variation among communities as they develop a discourse about superior and inferior scholarship, claims about truth, and the value of findings and their reporting. Given that communities differ in their epistemic commitments and the stability of their problem sets, we should get purchase on how advance and cumulation is registered. Let us now ask, How does progress and cumulation occur in sociology?

\section{PROGRESS AND CUMULATION IN SOCIOLOGY, A FRAGMENTED FIELD}

Disciplines may contain many subdisciplines. To the extent that a community of scholars is coterminous with a subdiscipline, as often happens, the analysis of disciplinary structure illuminates progress and cumulation in the constituitive communities. Where there are many topics and subdisciplines, where there are few specifications of connections among the topics, and where there are strong disagreements about methods that help create noncommunicating communities, the discipline resembles an "adhocracy." Whitley (1984), drawing on the organizational theorist Henry Mintzberg (1979), sees sociology as an adhocracy with little integration across subdisciplines. An "adhocracy" is an organization in which the various units have little to do with each other and have different views of what the enterprise is about, but each makes claims about its own contribution to the overall organization-there is at least that much awareness that the units are part of the larger organization and gain legitimacy, status, and resources from participating in it. To understand progress and cumulation in sociology, then, is to examine the texture of knowledge in the many communities contained in whole or in part within the discipline. 
Sociology has been a brawling, inchoate discipline. In The Impossible Science, Stephen and Jonathan Turner (1990) treat the cycles and trends that have occurred in American sociology over its history. One cycle has been the oscillation between what might be called knowledge for its own sake and social problem and civilizational concern. A related cycle is an oscillation in concern with scientific methodological purity. Depending upon both external and internal issues, these axes of orientation may combine or conflict in a variety of ways. For instance, methodological purity emphases may be combined with applied concerns, leading to an emphasis on evaluation research. Or, methodological purity may be combined with a knowledge for its own sake emphasis, leading to what $\mathrm{C}$. Wright Mills called "abstract empiricism."

Trends include a continuing growth of substantive specializations and methodological techniques. Although the American Sociological Association's membership has not grown much in absolute numbers over the last two decades, the number of organized sections has more than doubledthere are now over 25 . New specializations, represented by sections, may overlap considerably with older ones; nevertheless, each new section represents some focus of attention on a redefined or new central topic and defines a somewhat new community.

Turner and Turner do not draw out the implications of their analysis for progress and cumulation, or the perception of progress and cumulation. However, they tend to be pessimists: Because sociology is inchoate and various groups cannot (will not) agree on core problems and methods, sociology is doomed to wander in the wilderness. Progress and cumulation are unlikely. Although they do not explicitly discuss their epistemological commitments, I suspect that they tend to be foundationalists. But if one rejects foundationalism and accepts a community-based definition of knowledge, quite a different set of conclusions emerges.

If sociology had an overarching paradigmatic consensus, progress would be examined in terms of solving and posing questions related to the paradigmatic agreements and assumptions. Since it lacks that consensus, progress, and cumulation are measured against the problems and topics being debated, studied, disposed of, and succeeded in particular communities of scholars. In disciplines with strong paradigmatic consensus, introductory texts are likely to cover similar topics, have a shared language, and exhibit a consensus on the core. In an adhocracy such as sociology, however, cumulation occurs in the subdisciplines and introductory texts will vary because few writers will agree on the core topics, concepts, and communities that need to be represented.

Moreover, in the human sciences in general, and sociology in particular, communities vary in the extent to which their core problems are af- 
fected by large societal events and/or broad intellectual currents. Thus, the subdisciplines of sociology may well vary in the extent to which their orientations and concerns are shaped by the larger moral and political milieu.

Let me give a somewhat cursory overview of progress and cumulation in four communities within sociology-ethnomethodology, historical sociology, demography, and collective behavior/social movements. These four were chosen because they manifest a variety of epistemic commitments and trajectories of advance and cumulation. In the first instance, I attempt to represent progress and cumulation as it might be seen from within the community.

\section{Ethnomethodology}

Ethnomethodology has comprised a community of scholars committed to analyzing the core problem of how intersubjectivity is reached among interactants in a local setting. Whether the local setting is the negotiation of sexual identity, cab drivers and their dispatchers, young doctors learning to be gynecologists from other gynecologists and related practitioners, or welfare workers in a welfare bureaucracy, the task is to examine the devices of interrogation, the markers of agreement (indexicality), and the mechanisms for sustaining social understandings and cognitive order of microinteraction and changing interactional directions. Although not opposed to experimental intervention, for instance presenting subjects with someone with a false identity, the community disavowed quantitative analysis of interaction. Close logical analysis of the implications of verbal signing has been the core method. Although, it has been deeply committed to close analysis of language and conversation, ethnomethodologists are different from sociolinguists, who often have had a more descriptive and processual orientation, and semioticians, who are concerned with substantive meaning. The community of ethnomethodologists overlaps several other communities-it has boundaries (and disagreements) with phenomenologists, students of occupations and organizations, and socio-linguists.

The community took large steps in the late 1960s and 1970s. Progress occurred when the community agreed to conceptual distinctions and statements about when interactants can be thought to have achieved intersubjectivity or when intersubjectivity was defeated. Since the community disavowed the logic of covering law models, it neither developed general propositions, nor statements of variance. Progress was contained in a set of interlinked papers that most members of the community read and discussed (Heritage, 1984). A review of the paradigmatic papers would reveal a succession of debates in which the later papers built on the earlier ones, 
sharpening distinctions and adding new ones. A taut and tightly reasoned style dominated. By the mid-1980s, the core problems may have been exhausted (but see Pollner, 1991), yet the methods of close analysis of language turns and referentiality could be applied to a wide variety of problems. As attention shifted from the core problems, the community became less distinctive in its concern. In some regard it merged with sociolinguistics and conversation analysis, on the one hand, and substantive sociological topics like political sociology, gender relations and analysis, medical sociology, etc., on the other (Drew and Heritage, 1992). Today recruitment to the community has slowed and fewer sociologists call themselves ethnomethodologists.

\section{Historical Sociology}

An interest in large-scale historical change has been part of sociology since its inception, and scholars such as Weber were lauded for their historically based studies of societies. Yet prior to the 1950s, few in American sociology carried out detailed historical analyses in a sociological mode. Beginning in the 1950s, expanding rapidly in the 1960s and continuing since there has been a massive expansion and transformation of the community of historical sociologists (Abbott, 1994; Smith, 1991). One might argue that historical sociology is a field, not a community, since so many topics can in fact be treated with an historical, over time, orientation. After all, every societal institution, category, or process can be given an historical dimension. Conceivably equal attention could be paid to such topics as the history of schooling, the transformation of cities, the history of administration, etc. Moreover, as Abbott (1994) argues, all studies of social process, no matter how micro, have an implicit overtime orientation, and are thus historical. However, the agenda of historical sociology was heavily shaped by its ties to and emergence from political sociology with a left-liberal slant. The core problems grew out of an attempt to understand the social response to industrialization and the transformation of capitalism. Two interlaced topics dominated when the focus was on the internal developments of nationsfirst and foremost a materialist-class based analysis of the relationships of types of workers and types of elites, and second, and tied to external relations, the growth and transformation of the state. Later sociologists with a strong interest in less developed countries reacted to contemporaneous economic and political trends to redefine older topics such as imperialism in terms of dependency and world systems theory.

Methodologically, the community, especially the first generation, focused on secondary data and interpretation, rarely venturing into archives. 
Moreover, even when they used archival material, their ties to the larger sociological community led them to transform archival information into quantitative indicators of conflict or industrial structure.

From Barrington Moore, to Tilly, Skocpol, Wallerstein, and beyond, enormous progress has been made. Sharp controversies about the interplay of class formation, state formation, state autonomy, and world system theory generated serious and detailed analyses. Reuschemeyer et al. (1992) represent a culmination of the tradition energized by Moore. Obviously, the study of revolution and societal transformation remains viable. Thus, one can see continuity of problems, new perspectives brought to bear on older problems, evidence assembled, and some sense of advance.

Yet there have been changes in epistemic assumptions and in core problems. For one, the larger meta-narratives have been questioned. Moreover, positivistic epistemic assumptions have been shaken, leading to a healthy debate about methods and an opening toward culture and narrative analysis. Second, the growth of feminist theory has transformed the problem agenda. Historical sociology more than many areas has moved to make gender a central problematic. Finally, as a focus on context and local study emerged, and as the dominant political/macro focus of analysis receded, the unity of the community may have disappeared. The demise of grand meta-narratives and their clashes may appear to mean a decrease in intellectual breakthroughs, while a process of accumulation on many fronts goes on.

The historical sociology community is much larger than the ethnomethodological one. It is deeply interconnected to a national and international community of historians and other social scientists with interests in varieties of social history. However, it is still the case that historians and historical sociologists often view each other over a divide: With a few exceptions, sociologists, their theories, and their findings, have only a small audience among more traditional historians, even while a new generation of historians is more closely linked to the social sciences than their progenitors.

\section{Demography}

Both ethnomethodology and historical sociology have ties to fields and approaches long considered part of the humanities. Demography separated earlier from natural and moral philosophy and has its roots in social statistics. In some ways linked to human biology and in other ways to the needs of the administrative state, demography is "big science" compared to the other communities we have considered. Its location within sociology 
is somewhat accidental and it has sometimes made claims for autonomy from sociology and location elsewhere in the academy.

Either it uses the data bases of the administrative state-national censuses, epidemiological surveys, morbidity and mortality data-or it collects data on large samples, in many nations. Philanthropic foundations and government agencies fund these data collection efforts and, indeed, have played a large role in promoting and expanding the domain of demography around the world. Although demographic events and processes have large implications for many aspects of social life-from community integration and socialization, to the health and welfare of populations, to economic growth and change, to party politics-the agenda of demography is set to a larger extent than in most social science disciplines by the agenda of the state and major funding agencies. When family planning and birth control is perceived as a large problem, funds are committed to relevant studies. When societal interest switches to migration and immigration, a different part of the demographic equation is examined.

The demographic community, more than any of the others discussed, has made a wholesale commitment to positivism, especially of an empiricist kind. There is a large commitment to data quality and data sets. Theoretical ideas are close to the ground. Although Marxist or neo-Marxist theories of the relationship of households to production systems play a role in demographic thinking, demographic theories tend to have clear indicators and testable propositions. Although gender issues have become important in demography, especially the relationship of the changing status of women to a host of household compositional issues, feminist theory more generally has not.

The commitment to precise measurement ties demography to advances in statistics that are fairly precise and clear in their consequences for estimation. Advance in statistical techniques tied to computer processing capacity allows for more complex modeling of larger data sets, with a greater range of variables. Within the community of demographers, the reasons why earlier methods have been superceded is clear, even though debate often is quite fierce and some social statisticians argue that the application of more "sophisticated" tools often leads to difficult to interpret findings and a violation of statistical assumptions.

In American sociology population studies were tied to ecology. Over the last two decades the field has changed significantly in its dominant interests and connections. For a while, roughly from the mid-1950s until the mid-1970s, the statistical focus upon aggregate changes in large samples was applied to studying the distribution of status and prestige in the stratification order. In more recent times, ecological and stratificational interests have declined, while social epidemiological issues have come to the fore. 
The core may be represented by mathematical demography and stable population theory, which provides accounting identities around which the field is organized (Preston, 1993). Thus, even though topics recede from the agenda and others come to the fore, a sense of continuity and cumulation is achieved. More is known about birth rates, death rates, and migration and their interpenetration with social and economic processes. Demographers can cite area after area where empirical findings have clarified our knowledge of such matters as the cost of divorce, or the relationship of social indicators to mortality and morbidity, or the relationship of birth control programs to birth rates, or to the causes and consequences of single-headed families.

At the same time, the larger intellectual currents sweeping the social sciences and the humanities often have been marginalized. It is not that demographers are unaware of the importance of societal definitions for either their own research agenda or for the definitions of their key terms. Demographers know, for instance, that racial categories are social constructs, that natalist and immigration policies are the result of political-social processes. In recent times, the impact of culture on demographic processes has become an important topic. But these larger currents do not challenge the core commitments of the epistemic community. They may nuance the discussion, or denaturalize and deuniversalize some concepts, or introduce new variables for analysis, but the discourse proceeds within the commitments to large data sets, statistical estimation and core population variables.

\section{Collective Action/Social Movements (CA/SM)}

In contrast to demography, whose core topics were strongly linked to specific statistical modes of analysis, and concepts, such as cohorts, that had clear methodological implications, CA/SM has been driven more by theoretical and conceptual developments and has been quite eclectic in its methodological commitments. Originally, CA/SM largely organized around descriptive case studies, but increasingly a variety of methods have been employed-experimental studies of collective action in small groups, computer simulations, detailed observational studies of collective action events, such as protests and riots, codings and quantitative analysis of CA/SM activities as reported in the media, event-history analyses of the births and deaths of SMOs, and so on.

The study of social movements and collective behavior was transformed by the political events of the 1960s and the intellectual currents of the social sciences of the 1960s, first, and then the 1970s and 1980s. The 
political events - the rise of the civil rights movement and the student and anti war movements-normalized social movements. Where the Chicago School approach tended to lump social movements with collective behavior (riots, panics, fads, public opinion), the irrationalist assumptions sometimes assumed to undergird that clustering were challenged by those who saw political movements as politics by other means.

The newer resource mobilization approaches explored the implications of assuming that social movement and collective action activity was in some sense rational, responding to a sometimes implicit, sometimes explicit, calculation of costs and benefits. One of the great achievements of social science, and social movement theory in particular, was to problematize "interests." Most political scientists and sociologists had assumed an automatic link between interest and action. Although he was not the only one to raise the issue, Mancur Olson's (1965) important Logic of Collective Action cast starkly the free rider, mobilization, and collective action dilemma. The Resource Mobilization/Collective Action paradigm became the dominant paradigm (Morris and Herring, 1987; Zald, 1992). The Political Process approach was a major restatement and extension for political movements. Even though these approaches became dominant, many social movement scholars did not and do not buy into these approaches and older traditions retain vitality.

By the end of the 1970s, the growth of the new social movements (the women's, gay rights, and environmental movements), with their focus on social redefinition, consciousness-raising, and identity, presented a challenge to these earlier approaches, which assumed agreed upon social categories and definitions of injustice. In a sense, New Social Movement theorists problematized interests in a different way: Where CA/SM scholars problematized mobilization, New Social Movement scholars problematized identities that lead to interests.

Moreover, in the United States, borrowing from Goffman, analytic and methodological approaches to the study of frames (i.e., the way symbols and phrases define problems and potential solutions), cognitive constructs, and symbolic packages provided tools for the examination of discourse. Matters of ideology and culture are more prominent in this community today than they were 15 years ago, yet the turn to discourse and culture is often treated without historical and cultural depth, in part because the community focuses mainly on contemporaneous movements and recent battles. Currently the "hot" end of the field is focusing on political process models and framing, yet the mobilization/collective action approach retains a fair degree of viability.

This area reveals an almost Lakatosian process of research program development and change. More influenced by events in the larger society 
than many areas in social science or sociology, and open to intellectual currents in the humanities as well, it is less open than historical sociology to these latter currents.

Although within the community there is a great sense of advance and cumulation, not all who work in this area see the process so benignly. Piven and Cloward (1991), for instance, believe that the normalization of protest in social movement theory leads to an underestimation of the importance and value of disruptive and less organized protest. From a different slant, James Rule $(1988,1994)$ argues the choice of approaches has been more a function of expressive taste than logic and observation, and that the shift from older approaches has led to important losses of topics from the research domain. Thus, he thinks, we may only be seeing a faddish shift in focus. While there have been losses, such as scholars' tendency to underestimate the role of hot emotions in fueling movements and collective action, losses occur in many fields when paradigms shift. The gains from the newer work have been substantial.

These communities differ quite substantially in their ability to generate cumulative knowledge and to progress over their recent histories. Arguably, the demographic community, because it agrees on a core set of population components with measurable dimensions, is well structured for cumulation, not around a hierarchically ordered set of theoretical propositions, but around a set of topics with well-defined parameters. But the intellectual strategy tends to be incremental and is not conducive to large steps forward. Historical sociology, which made large progress as it blocked in major explanatory schemes for major social processes, may be in the process of splintering. As meta-narratives are brought into disrepute, strong unifying themes, tying researchers together, vanish. Alternately, since historical sociology inherited political sociology's emphasis on moral and political concerns-it has attracted the left within the discipline-those same concerns may structure the agenda. But without unifying meta-narratives, progress may come more by examining new areas than by developing encompassing explanations (see Lloyd, 1993, who argues for the enduring value of a macrostructuralist agenda). It may be that cumulation will occur around narrower topics. I should add, however, that the fact that historical sociology bridges to intellectual history and the humanities makes it more open than some other sociological communities to broader intellectual currents. Ethnomethodology made enormous progress early, but has been diffused into conversation analysis and applied concerns. There is some reason to believe that a market for ethnomethodology, narrowly conceived, never developed. It is difficult to separate the political economy of the field, which then limits the possibilities of research, from a fading intellectual agenda. However, ethnomethodology was cumulative, in the sense that later work 
was based on earlier work, but because of a narrow agenda, around sharper analytic distinctions. Empirical generalizations were never its goals. Finally, the study of social movements made large strides, but is now in a period of consolidation. There are large sets of problems that have not been well investigated; for instance, only recently has the transnational nature of collective action and social movements come onto the agenda, but the contours for major advance may be past-for now.

Other fields or communities in sociology would reveal quite different patterns. Cultural sociology, for instance, has been on the upswing, with a heightened sense of controversy and progress. For almost two decades the sociology of organizations has been shaped by two or three large theoretical agendas, although other approaches have continued to flourish. What appears to be clear is that progress has been rapid in some subcommunities, incremental in others, and barely happening in still others. What we cannot do is draw conclusions about progress and cumulation in the discipline as a whole.

\section{PROBLEMS, PROGRESS, AND CUMULATION IN INTERPRETATIVE COMMUNITIES}

It is likely that this approach can be applied to many of the communities that make up the social sciences. In some of them we may even be able to speak of progress and cumulation in a discipline, if the discipline has an overarching paradigm that guides subdisciplines and communities that comprise it. Economics is the most likely current candidate. But can this approach work in disciplines and communities less organized around research problems, more oriented to a community discussion and interpretation of shared objects of attention? Does it work in communities where the language of truth claims seems alien to the community? Where there is little attempt to disprove or validate others claims? Where in fact only a very few people identify a common problem, even though they share broad intellectual orientations and commitments to modes of argument and evidence?

With some qualifications, I think the main contours of the argument hold. First, interpretative communities vary among themselves in their methodological commitments. Although most give primacy to texts, the use of texts varies considerably. In some the text is the basis for a conversation. In much of contemporary Anglo-American philosophy, for instance, footnotes are lightly used, argument is logical, and great attention is given to definitions and consequences of alternative definitions. In others, the text is heavily footnoted and the footnotes refer not to other scholars' interpre- 
tations but to historical/linguistic evidentiary claims. The dialogue with other contemporaneous scholars is minimized.

In many interpretative communities a clear succession of problem topics can be seen, or new topics coming on, and old topics leaving. Moreover, a similar transformation of communities can be seen, as the utility of older ways of studying subjects is found to be wanting. For instance, the philosophy of science has been radically reconfigured, opening up to the history and, possibly, the sociology of science in ways in which the older philosophy of science did not. (Some philosophers of science still operate in a pure analytic/epistemological mode attempting to preserve an uncontaminated realm.) Other areas of philosophy proceed in the same analytic mode that they have for decades. Similarly, it is obvious that over the last 70 years there have been significant shifts in literary theory, which many practitioners would evaluate in terms of progress or advance, even though outsiders might not validate those claims; I am sure that criteria of goodness and badness, of betterness, will be found in almost all communities. I am less clear about the question of cumulation in interpretative communities and leave it for further discussion. It may be that there is progress in problem definition, and cumulation of facts, but that changes in problem definition operate more to rule out interpretations than provide scaffolding for inclusion and cumulation. To the extent that interpretative glosses are not lost, possibly we can speak of interpretative cumulation. At the very least, the reigning interpretative glosses set the stage for the next generation as they use evidence and logic in a community dialogue.

\section{CONCLUSIONS}

The core of my argument is that the collapse of foundationalism and linear models of scholarly progress has created a gap in our self-understanding of what we as scholars are about. Older notions of progress and cumulation have to be revisited. Here progress, or advance, has been at least partially separated from cumulation, the processes of retention, transmittal, and recycling. Different fields of knowledge will vary in the stability of their problem sets, in the degree of consensus about what is an advance, in the recognition of and recycling of those advances by neighboring communities of scholars, even in the extent to which their fields are organized around problems or broader discursive topics.

I have chosen to think of progress and cumulation in terms of community practice, epistemic commitments, and organization. Since sociology is a fragmented discipline, progress and cumulation have to be seen in the contexts of the subdisciplines/communities that compose it. Here we have 
sketched progress and cumulation in four communities, ethnomethodology, historical sociology, social movements and collective action, and demography. In the first instance, advance and cumulation is internally viewed and used, even though the importance and valuation of those advances may largely depend upon the judgments and valuation of external audiences, and the relevance of findings and interpretations to others' life-worlds. After all, scholarship becomes largely an avocational affair, if deans, students, other scholars, funding agencies, and the broader public cannot connect to the scholarship in some way. Still, amateur scholarship can pursue truth, and amateur communities can be epistemic communities.

I do not rule out other, more holistic critiques of the very enterprise, which emphasize the political constitution of communities (Rouse, 1987). There are no transcendent truths in this approach-it is communities all the way down. In this paper, I have only alluded to the political economy of scholarly communities. The sociology of science has at least two large, though interconnected, agendas-one accounting for the intellectual constitution of communities, the other tying it to the flow of resources and rewards. In recent years, the former has received more attention. Moreover, the sociology of the human and social sciences is much less developed than the sociology of the natural and physical sciences. If we do develop the sociology of the human sciences, we have to pay attention to a key resource flow rarely mentioned in the sociology of science, the flow of students and the interplay with publishers, mass media, and audiences. Many of the human sciences are less internalized than the natural and physical sciences; their ideas arise from and are more easily assimilated to the larger cultural milieu. Understanding these processes represents a real opportunity. My sense is that an exciting field remains to be explored.

\section{ACKNOWLEDGMENTS}

A large number of colleagues have helped me think through the issues of this paper. I owe a debt of gratitude to Renee Anspach, Gerry Bruns, Stephen Cole, Phil Converse, Lowell Hargens, Michael Kennedy, Arthur Kleinman, Silvia Pedraza, Kim Scheppelle, Mark Schneider, Howard Schuman, and Margaret Somers. Several of these conversations took place while I was a Fellow at the Center for Advanced Studies in the Behavioral Sciences, Palo Alto, in the winter of 1994. Once again, the Center proved to be an extraordinary environment for reflection. 


\section{REFERENCES}

Abbott, Andrew

1994 "History and sociology: The lost synthesis." In E. Monkkonen (ed.), Engaging the Past: The Uses of History Across the Social Sciences: 77-112. Durham, NC: Duke University Press.

Berelson, Bernard and Gary A. Steiner

1964 Human Behavior: An Inventory of Scientific Findings. New York: Harcourt, Brace.

Campbell, Donald

1969 "Ethnocentrism of disciplines and the fish scale nodel of omniscience." In M. Sherif (ed.), Interdisciplinary Relationships in the Social Sciences: 328348. Chicago: Aldine.

Cole, Stephen

1992 Making Science: Between Nature and Society. Cambridge, MA: Harvard University Press.

1994 "Why sociology doesn't make progress like the natural sciences." Sociological Forum 9:133-154.

D'Andrade, Roy

1985 "Three scientific world views and the covering law model." In D. W. Fiske and R. A. Shweder (eds.), Metatheory in Social Science: Pluralisms and Subjectivities: 19-41. Chicago: University of Chicago Press.

Drew, Paul and John Heritage, eds.

1992 Talk at Work: Interaction in Institutional Settings. Cambridge, UK: Cambridge University Press.

Dupre, John

1993 The Disorder of Things: Metaphysical Foundations of the Disunity of Science. Cambridge, MA: Harvard University Press.

Fleck, Ludwig

1935/1979

Genesis and Development of a Scientific Fact. Chicago: University of Chicago Press.

Giddens, Anthony

1978 "Positivism and its critics." In T. Bottomore and R. Nesbit (eds.), A History of Sociological Analysis: 237-286. New York: Basic Books.

Gilbert, G. Nigel and Michael Mulkay

1984 Opening Pandora's Box: A Sociological Analysis of Scientists' Discourse.
Cambridge, UK: Cambridge University Press.

\section{Hacking, Ian}

1984 "Five parables." In R. Rorty, J. B. Schneewind, and Q. Skinner (eds.), Philosophy in History: Essays on the Historiography of Philosophy: 103124. Cambridge, UK: Cambridge University Press.

Heritage, John

1984 Garfinkel and Ethnomethodology. Cambridge, UK: Polity Press.

\section{Horwich, Paul}

1993 World Changes: Thomas Kuhn and the Nature of Science. Cambridge, MA: MIT Press.

Kitcher, Philip

1993 The Advancement of Science. New York: Oxford University Press.

\section{Kuhn, Thomas}

1977 The Essential Tension. Chicago: University of Chicago Press.

\section{Laudan, Larry}

1977 Progress and its Problems. Berkeley: University of California Press.

Lloyd, Christopher

1993 The Structures of History. Oxford, UK: Blackwell.

Mayr, Ernst

1982 The Growth of Biological Thought: Diversity, Evolution and Inheritance. Cambridge, MA: Harvard University Press.

McCloskey, Donald N.

1985 The Rhetorics of Economics. Madison: University of Wisconsin Press.

Mintzberg, Henry

1979 The Structuring of Organizations: A Synthesis of Research. Englewoods Cliffs, NJ: Prentice-Hall.

Morris, Aldon, and Cedric Herring

1987 "Theory and research in social movements: A critical review." In Samuel Long (ed.), Political Behavior Annual. Norwood, NJ: Ablex.

Olson, Mancur

1965 The Logic of Collective Action. Cambridge, MA: Harvard University Press.

Pollner, Melvin

1991 "Left of ethnomethodology: The rise and decline of radical reflexivity." American Sociological Review 56: 70-80. 
Piven, Frances Fox and Richard A. Cloward

1991 "Collective protest: A critique of resource mobilization theory." International Journal of Politics, Culture and Society $4: 435-458$.

Preston, Samuel

1993 "The contours of demography: Estimates and projections." Demography 30:593-606.

Rorty, Richard

1980 Philosophy and the Mirror of Nature. Princeton, NJ: Princeton University Press.

Rouse, Joseph

1987 Knowledge and Power: Towards a Political Philosophy of Science. Ithaca, NY: Cornell University Press.

1990 "Narrative Reconstruction of Science," Inquiry 33:179-196.

1991 "Philosophy of Science and the Persistant Narratives of Modernity." Studies in History and Philosophy of Science 22:141-162.

Rueschemeyer, Dietrich, E. H. Stephens, and J. D. Stephens

1992 Capitalist Development and Democracy. Chicago: University of Chicago Press.

Rule, James B.

1988 Theories of Civil Violence. Berkeley: University of California Press.

1994 "Dilemmas of theoretical progress." Sociological Forum 9:241-258.

Shapere, Dudley

1984 "Reason and the Search for Knowledge: Investigations in the Philosophy of Science." Vol. 78 in Boston Studies in the Philosophy of Science, Robert S. Cohen and Marx W. Wartofsky (eds.), Boston: D. Reidel Publishing Co.

Smith, Dennis

1991 The Rise of Historical Sociology. Cambridge, UK: Polity Press.

Somers, Margaret forthcoming

"Where is social theory after the historic turn? Knowledge cultures and historical epistemologies in social analysis." In $\mathrm{T}$. McDonald (ed.), The Historic Turn in the Social Sciences. Ann Arbor: University of Michigan Press.

\section{Stinchcombe, Arthur}

1994 "Disintegrated disciplines and the future of sociology." Sociological Forum 9:279-292.

\section{Taylor, Charles}

1971 "Interpretation and the sciences of man." Review of Metaphysics 25: 1. Reprinted in P. Rabinow and W. M. Sullivan (eds.), Interpretive Social Science: A Reader: 25-72. (1979). Berkeley, CA: University of California Press.

Turner, Jonathan and Stephen Turner

1990 The Impossible Science: An Institutional Analysis of American Sociology. Newbury Park, CA: Sage Publications.

Whitley, Richard

1984 The Intellectual and Social Organization of the Sciences. Oxford, UK: Clarendon Press.

Zald, Mayer $\mathbf{N}$.

1991 "Sociology as a discipline: Quasi-science and quasi-humanities." American Sociologist 22, 165-187.

1992 "Looking backward to look forward: Reflections on the past and future of the resource mobilization research program." In A. D. Morris and C. M. Mueller, (eds.), Frontiers in Social Movement Theory: 326-350. New Haven, CT: Yale University Press.

Zetterberg, Hans L.

1963 On Theory and Verification in Sociology. Totowa, $\mathrm{NJ}$ : Bedminster Press. 